\title{
Dependence of ultrasonic contact impedance hardness on Young's modulus of elasticity of creep-resistant steels
}

\author{
Michal Junek, Jiří Janovec, Petr Ducháček \\ CTU in Prague, Faculty of mechanical engineering, Department of Materials Engineering, Praha 2, Karlovo náměstí 13, Czech Republic
}

ABSTRACT

The paper deals with the hardness measurements by mobile UCI hardness testers as a means of determining the residual operation life of power unit components. It aims to answer questions regarding the level of dependence of UCI hardness on Young's modulus of creep-resistant steels and determining the conditions of a $\mathrm{UCl}$ hardness tester calibration. The experimental part describes comparative measurements of hardness values obtained using stationary hardness testers and UCI hardness testers.

Section: RESEARCH PAPER

Keywords: ultrasound hardness tester; Young's modulus of elasticity; calibration; creep-resistant steel; residual operation life

Citation: Michal Junek, Jiři Janovec, Petr Ducháček, Dependence of ultrasonic contact impedance hardness on Young's modulus of elasticity of creepresistant steels, Acta IMEKO, vol. 6, no. 1, article 5, April 2017, identifier: IMEKO-ACTA-06 (2017)-01-05

Section Editor: Konrad Jędrzejewski, Warsaw University of Technology, Poland

Received March 2, 2016; In final form March 17, 2016; Published April 2017

Copyright: (C) 2017 IMEKO. This is an open-access article distributed under the terms of the Creative Commons Attribution 3.0 License, which permits unrestricted use, distribution, and reproduction in any medium, provided the original author and source are credited

Funding: This work was supported by the Ministry of Education, Youth and Sport of the Czech Republic within the project No. LO1207 of the program NPU1

Corresponding author: M. Junek, e-mail: michal.junek@fs.cvut.cz

\section{INTRODUCTION}

At present a trend of developing hardness measurements by portable hardness testers exists, allowing "non-destructive" hardness measurements of large construction parts without any need of specimen separation for stationary hardness testers. Four physically distinct methods used are: UCI ultrasonic method, dynamic rebound method, optical method TIV (Through Indenter Viewing) and electrical resistance method (Handy Esatest). In the following text, the focus was aimed only on the UCI method.

One of the many possibilities of using portable UCI hardness testers is the hardness measurement in assemblies (steam boilers, steam pipe-lines) functioning in energy units, which operate in creep conditions (temperature approx. $550{ }^{\circ} \mathrm{C}$ and a pressure approx. $\left.15 \mathrm{~N} \cdot \mathrm{mm}^{-2}\right)$. Long-term operation $\left(2.5 \times 10^{5}\right.$ hours $)$ in these conditions leads to degradation of the material accompanied by a decrease of the hardness values. UCI hardness measurement method should thus serve to detect thresholds hardness values that indicate the poor mechanical properties of the material, the risk of failure and the necessity of a more thorough examination of the experimental material state (microstructure evaluation, small punch samples preparation).

\section{THE UCI METHOD OF HARDNESS MEASUREMENT}

An UCI probe consists of a Vickers diamond tip attached to the end of a metal rod, which is excited to perform a longitudinal oscillation with a frequency of $70 \mathrm{kHz}$, by piezoelectric transducers (Figure 1).

$\mathrm{T}$ is the piezoelectric transducer, $\mathrm{R}$ the piezoelectric receiver, $\mathrm{O}$ the oscillating rod, $\mathrm{V}$ the indenter (for example Vickers diamond) and $\mathrm{m}$ is the test material.

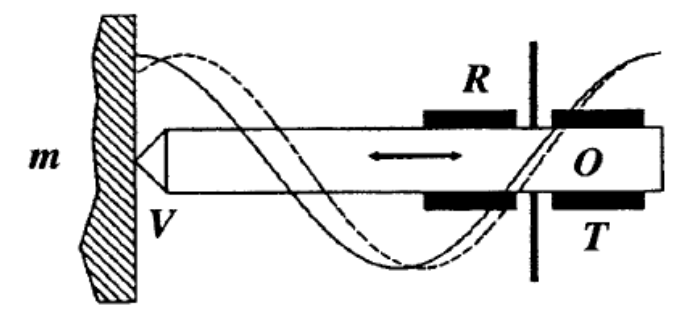

longitudinal amplitudes (no contact)

- - - - longitudinal amplitudes (in contact)

Figure 1. UCl probe schematics [1]. 
The UCI method does not require the diagonals of the test indentation to be measured which is necessary for the Vickers hardness determining. In this method, the shift of an ultrasonic frequency of the oscillating indenter is electronically related with the area of the indentation and thus resulting in the final hardness value. The deeper the diamond indenter penetrates, the larger is the indentation area, the larger the frequency shift of the diamond tip and the lower the resulting hardness, see (1), (2) and Figure 2 [2]

$\Delta f=f\left(E_{e f f} \cdot A\right)$,

$H V=F / A$,

where $\Delta f$ is the frequency shift, $E_{\text {eff }}$ the effective modulus of elasticity (contains the elastic constants of both the indenter and the test piece), $A$ is the area of indentation, $H V$ the Vickers hardness value and $F$ is the test load.

Equation (1) implies that a frequency shift depends on the effective modulus of elasticity as well. Therefore, Young's modulus of elasticity in tension must be considered using the UCI method in practice. The equipment must be calibrated when determining the hardness of different materials with different hardness values. But the question is: to what extent does the UCI hardness depend on the modulus of elasticity? [2]

\subsection{Calibration}

The ASTM A1038 - 05 standard [1] states that a UCI hardness tester usually has been calibrated on non-alloyed and low-alloyed steel, that is, certified hardness reference blocks with Young's modulus of elasticity equal to $210000 \mathrm{~N} \cdot \mathrm{mm}^{-2}$. Because unalloyed or low-alloy steels have a similar Young's modulus of elasticity, accurate results are obtained with the standard calibration. In many cases, the difference in Young's modulus of medium-alloy and high-alloy steels is so insignificant that the error created falls within the allowable tolerances of the part. But the question is: what is considered as a similar Young's modulus of elasticity?

Hardness reference blocks are needed for calibration to other materials with a different Young's modulus of elasticity. This paper should answer the question of calibration UCI hardness testers used for hardness measurement of components functioning in power units.

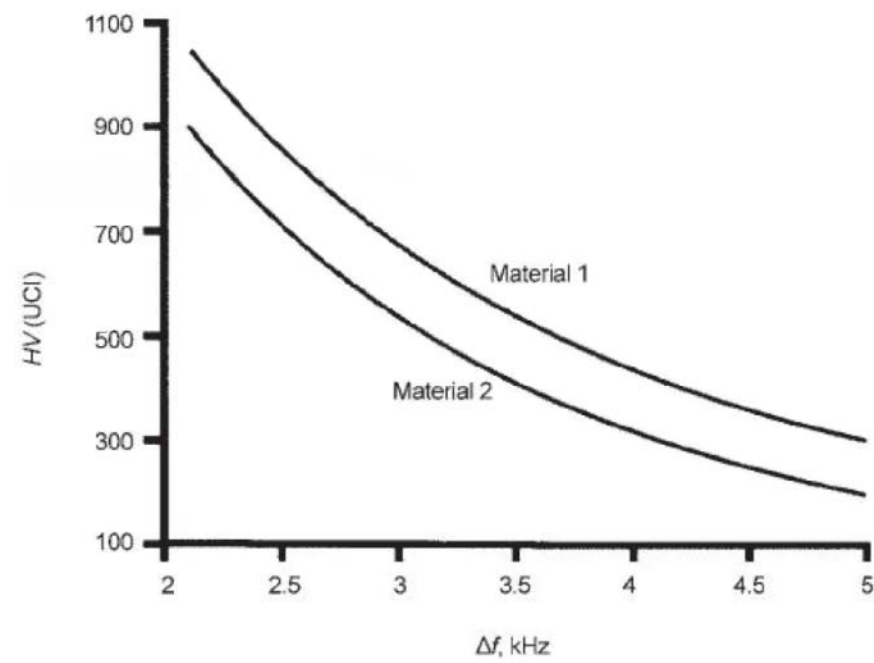

Figure 2. Frequency shift of an ultrasonic contact impedance (UCI) probe as a function of hardness [3].

\subsection{Comparison of non-destructive methods of hardness measurement}

Several methods for non-destructive hardness measurements are used in practice. Table 1 shows various methods for nondestructive measuring of hardness using portable hardness testers. Furthermore, a comparison of the areas of applications of each portable hardness testers is given. From this comparison, the UCI method seems to be best for hardness measurements of large construction parts functioning in energy units (steam pipe-lines, steam boilers and welds of these parts).

\section{DEGRADATION MECHANISMS OF HIGH PRESSURE (HP) STEAM PIPE-LINES}

The best resistance against operating in conditions of creep damage shows CrMoV low-alloy steels in the normalized or heat-treated state (13CrMo4-5, 14MoV6-3, 10CrMo9-10). In case of higher operating parameters, it is $9-12 \% \mathrm{Cr}$ martensitic steel X10CrMoVNb9-1 (P91) and X10CrWMoVNb9-2 (P92) steel. The main factors affecting the lifetime of HP steam pipelines is a combination of their material properties and operating conditions. The main degradation mechanisms therefore include material degradation in the form of structural changes caused by coagulation of carbide particles and the nucleation and formation of cavities due to creep damage. This

Table 1. Recommended applications for hardness measurement by portable hardness testers [2].

\begin{tabular}{|c|c|c|c|c|}
\hline Applications & $\begin{array}{l}\text { Dynamic } \\
\text { rebound } \\
\text { method }\end{array}$ & $\begin{array}{c}\text { UCl } \\
\text { method }\end{array}$ & $\begin{array}{c}\text { TIV } \\
\text { method }\end{array}$ & $\begin{array}{l}\text { Handy } \\
\text { Esatest }\end{array}$ \\
\hline Solid (big) parts & $*$ & $*$ & o & o \\
\hline $\begin{array}{l}\text { Coarse-grained } \\
\text { materials }\end{array}$ & $*$ & $x$ & $x$ & $x$ \\
\hline $\begin{array}{l}\text { Steel and aluminium } \\
\text { cast alloys }\end{array}$ & $*$ & 0 & 0 & 0 \\
\hline HAZ with welds & $x$ & $*$ & $*$ & $*$ \\
\hline $\begin{array}{c}\text { Tubes: wall } \\
\text { thickness }>20 \mathrm{~mm}\end{array}$ & $*$ & $*$ & $*$ & $*$ \\
\hline $\begin{array}{c}\text { Tubes: wall } \\
\text { thickness }<20 \mathrm{~mm}\end{array}$ & $x$ & $*$ & $*$ & $*$ \\
\hline $\begin{array}{l}\text { Inhomogeneous } \\
\text { surfaces }\end{array}$ & o & $x$ & $x$ & $x$ \\
\hline Sheet metal, coils & $x$ & 0 & $*$ & $*$ \\
\hline Thin layers & $x$ & 0 & $*$ & $*$ \\
\hline $\begin{array}{l}\text { Hard to get at } \\
\text { positions }\end{array}$ & $x$ & $*$ & $x$ & $*$ \\
\hline Coarse surfaces & $*$ & $x$ & $x$ & 0 \\
\hline $\begin{array}{l}\text { Finally machined } \\
\text { surfaces }\end{array}$ & 0 & $*$ & $*$ & $*$ \\
\hline $\begin{array}{c}\text { Electrically } \\
\text { conductive materials }\end{array}$ & $*$ & $*$ & $*$ & $x$ \\
\hline Dusty environments & $*$ & 0 & 0 & $x$ \\
\hline \multicolumn{5}{|c|}{ Explanatory notes to table: } \\
\hline \multicolumn{5}{|c|}{$\begin{array}{ll}\text { o } & \text { Sometimes suitable (In the case of elimination conditions } \\
* & \text { having adverse impacts on measurement results) } \\
* & \text { Especially well-suited }\end{array}$} \\
\hline
\end{tabular}


degradation is accompanied by a reduction of hardness. [4]

The structural changes are temperature and time dependent processes which could lead to a decrease in both short-term characteristics (yield strength, ultimate strength, hardness, and fracture toughness) and long-term characteristics (creep strength, creep deformation, plasticity). In case of low-alloy creep-resistant steels an area of predominant hardening and an area of predominant softening exists. Hardening of the material (up to 1000 hours of operation) in $\mathrm{CrMoV}$ steels is caused by additional precipitation of vanadium carbides, thereby increasing the number of new dispersed particles, reducing their average size, increasing their volume fraction and decreasing their interparticle distance. On the other hand, during material softening coarsening of dispersed particles via diffusion processes occurs, resulting in an increase of their average size, volume fraction decrease and increase of the interparticle distance [4].

Stages of degradation of creep resistant, low-alloy steel of chemical composition of $0.5 \% \mathrm{Cr}-0.5 \% \mathrm{Mo}-0.25 \% \mathrm{~V}$ (14MoV6-3) subjected to creep exposure are in Figure 3. Stage 0 corresponds to the initial state with a ferritic-bainitic structure at the beginning of creep exposure (Figure 3 - Stage 0). The first stage of structural changes is characterized by a moderate decomposition of bainite. That is accompanied by coagulation of $\mathrm{M} 3 \mathrm{C}$ carbides in these areas and further precipitation of M23C6 carbides along the ferritic grains boundaries. At the same time, very fine MC carbides precipitate within the ferrite grains (Figure 3 - Stage 1). The next stage is characterized by significant decomposition of bainite and coagulation of M3C carbides into relatively large carbide particles at the grain boundaries. The M23C6 carbides precipitate on the boundaries of ferritic grains and form chains. Simultaneously, fine $\mathrm{MC}$ carbides are observed within ferritic grains (Figure 3 - Stage 2). Final structural changes result in a ferritic matrix containing MC and M6C carbides inside ferrite grains and large M23C6 carbides precipitated along the grain boundaries (Figure 3 Stage 3). Depending on the operating conditions, the material may contain also other types of carbides, e.g. M7C3 carbides. After such a degradation of the material microstructure and further creep exposure creep cavities are formed [5].

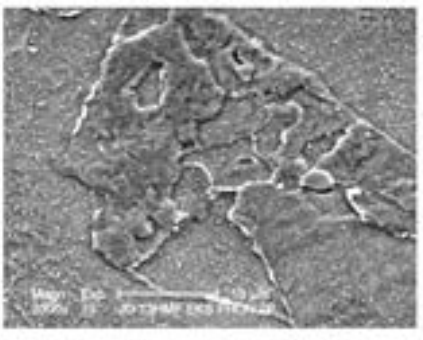

Stage 0: 160 - 180 HV10

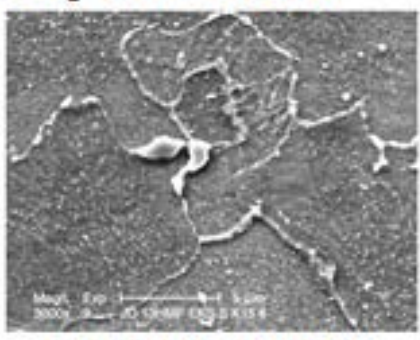

Stage 2: 140 - 150 HV10

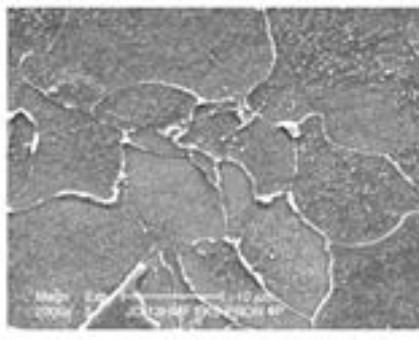

Stage 1: 150 - 160 HV10

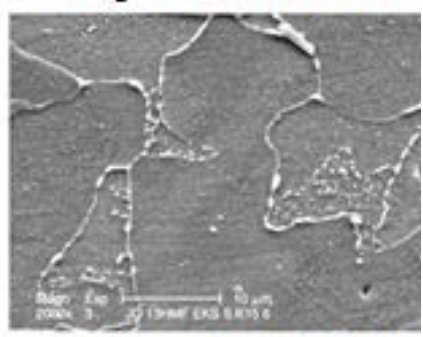

Stage 3: 120 - $140 \mathrm{HV} 10$
Figure 3. Stages of microstructure degradation after creep exposure [5].

\subsection{Surface Decarburization}

Surface decarburization takes place most frequently on the outer surface of steel components and is accompanied by rapid reduction of carbon content on the surface due to diffusion caused by high temperatures.

A decarburized layer has a lower hardness than the material below the layer due to reduced carbon content. The carbon content gradient in the decarburized layer increases with the distance from the outer surface, see Figure 4 and Figure 5. Therefore, the hardness values measured after removal of the decarburized layer are higher. Since the hardness is measured on the outer surface components, it is imperative to remove this layer in order to achieve relevant results. The decarburized layer has a thickness usually of up to $1.0 \mathrm{~mm}$.

\section{EXPERIMENTS}

The experimental part was focused on determining UCI hardness dependence on Young's modulus of elasticity in tension via comparative measurements of hardness values obtained by the classic HV10 Vickers method and values obtained using the UCI hardness tester. Deviation of the mean values measured by the UCI hardness tester and by the stationary (laboratory) hardness tester were evaluated.

\subsection{Used Measurement Equipment}

Comparative measurements as a means of determining the UCI hardness on Young's modulus of elasticity were performed in accord with the ĆSN EN ISO 6507-1 standard using a calibrated stationary hardness tester by the Vickers method with a load of HV10. As a representative of portable hardness testers the UCI hardness tester Krautkrämer MIC20 and Krautkrämer MIC10 with UCI probe MIC 2010 of load of $98 \mathrm{~N}$ was selected.

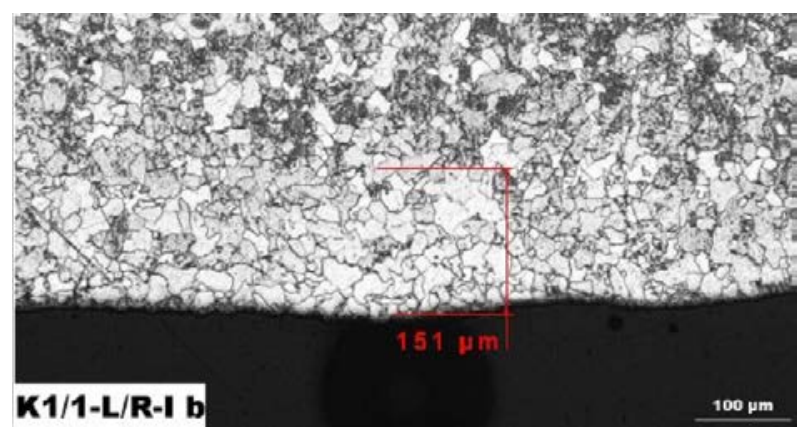

Figure 4. Surface decarburization of HP steam pipe-line of fossil fuel power plants.

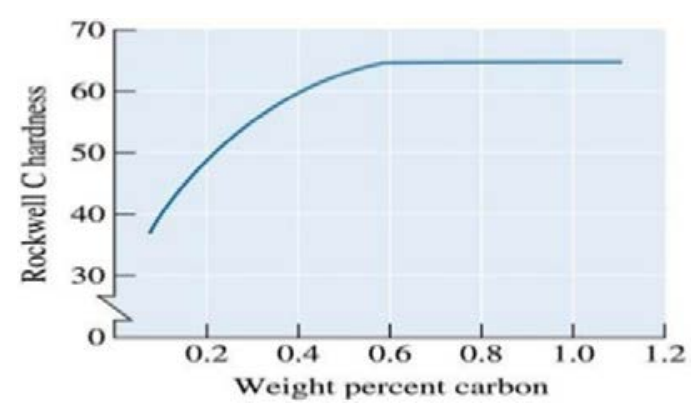

Figure 5. Dependence of Rockwell hardness on the carbon content [6]. 


\subsection{Experimental Materials}

Materials with different Young's modulus $E$ were selected for comparative measurements. Values of Young's modulus $E$ were verified using data from literature. The mean values without standard deviations are shown in Table 2. The experimental determination of the Young's modulus values was not carried out due to lack of time.

The experimental samples were removed from the steam pipe-lines or boiler tube in different states of degradation. In the case of steels X20CrMoV12-1 and X5CrNiCuNb17-4-4, it was possible to get the samples from the rotor blades. Table 3 shows a description of individual samples.

\subsection{Preparation of the Measurement Site}

Hardness of the materials described above was measured always on the outer surface (approximately 0.5 to $1.0 \mathrm{~mm}$ was grinded off in order to remove the decarburized layer), and across the tube wall thickness. In case of steels of a tensile modulus of $200 \mathrm{~N} \cdot \mathrm{mm}^{-2}$ hardness was measured only in the cross-section of the blade lock. The surface was prepared using a metallographic grinder with sandpaper grit of 400 , thereby achieving a surface roughness $R_{a}$ of $0.07-0.12 \mu \mathrm{m}$ (measured by a Surface Roughness Tester Hommelwerke LV-5E). The selected number of indentations on every surface was 10 .

\subsection{Measurement Process}

On the prepared surfaces with an approximate area of 10 $\mathrm{mm}^{2}$ at first the hardness was measured according to ČSN EN ISO 6507-1 using a stationary hardness tester (Vickers method) with a load of HV10. Subsequently, UCI hardness tester was used for hardness measurement in close vicinity (approximately $5 \mathrm{~mm}$ ) of these indentations.

During UCI tester measurements the following finding was observed. The probe MIC 2010 was firstly used for measuring

Table 2. Selected materials and their Young's modulus values.

\begin{tabular}{lc}
\hline \multicolumn{1}{c}{ Materials } & $\boldsymbol{E}\left[\mathbf{N} \cdot \mathbf{m m}^{-2}\right]$ \\
\hline X10CrMoVNb9-1 (P91) & 218000 \\
\hline 14MoCrWMoVNb9-2 (P92) & \\
T23 & 210000 \\
T24 & \\
\hline X20CrMoV12-1 & 200000 \\
X5CrNiCuNb17-4-4 & 193000 \\
\hline Steel Super 304H & \\
\hline
\end{tabular}

Table 3. Selected samples of materials and their state of operating (laboratory) degradation.

\begin{tabular}{|c|c|}
\hline Material & Sample - State of degradation \\
\hline \multirow{2}{*}{ X10CrMoVNb9-1 } & P6 - lab. ageing at $600{ }^{\circ} \mathrm{C} / 10000$ hours \\
\hline & P21 - initial state after heat treatment \\
\hline \multirow{2}{*}{ X10CrWMoVNb9-2 } & BT3 - lab. ageing at $650^{\circ} \mathrm{C} / 20000$ hours \\
\hline & T33 - lab. ageing at $650^{\circ} \mathrm{C} / 5033$ hours \\
\hline \multirow{3}{*}{ 14MoV6-3 } & $\mathrm{K} 1$ - degraded at $525^{\circ} \mathrm{C} / 240000$ hours \\
\hline & EPR - degraded at $560{ }^{\circ} \mathrm{C} / 261800$ hours \\
\hline & $\mathrm{EPC}$ - degraded at $540^{\circ} \mathrm{C} / 240066$ hours \\
\hline \multirow{2}{*}{ T23 } & V23 - initial state after heat treatment \\
\hline & $\mathrm{D} 23$ - lab. ageing at $650^{\circ} \mathrm{C} / 5033$ hours \\
\hline \multirow{2}{*}{$\mathrm{T} 24$} & V24 - initial state after heat treatment \\
\hline & $\mathrm{D} 24$ - lab. ageing at $650^{\circ} \mathrm{C} / 5033$ hours \\
\hline X20CrMoV12-1 & L1-Unknown \\
\hline X5CrNiCuNb17-4-4 & L2-Unknown \\
\hline Steel Super 304H & $2030-$ Dissolving annealing $1150^{\circ} \mathrm{C} / 2 \mathrm{~min}$ \\
\hline
\end{tabular}

the initial state hardness (without a fixture providing perpendicular positioning). Hardness values measured in this way showed significant deviations and unreal values. Therefore, it was decided to use the probe with a fixture providing perpendicular positioning to solve the problem. It implies that when measuring the hardness, it is necessary to keep the probe perpendicular to the surface, which can be achieved by installing a fixture or by a properly trained and experienced person performing the measurements.

\subsection{Measurements results}

All hardness measurement results are summarized in Table 3 to Table 10. The tables contain the average hardness values from 10 measurements for each sample measured on the surface and throughout the wall thickness by the laboratory hardness tester and by UCI hardness testers. The tables further include standard deviations (STD) of measured values and the deviation of the average value of the UCI hardness from average values measured by the stationary hardness tester (LAB).

a) Steels with $E=218000 \mathrm{~N} \cdot \mathrm{mm}^{-2}$

In case of steels with the same Young's modulus 218000 $\mathrm{N} \cdot \mathrm{mm}^{-2}$ the measurements show that the values of the deviations of both UCI hardness testers (Krautkrämer MIC20 and MIC10) vary in the same trend. The average value of the deviations is approximately $-21 \mathrm{HV}$ (see Tables 4 and 5).

b) Steels with $E=210000$ N.mm-2

In case of 14Mo6-3 steel and T23, T24 steels with the same Young's modulus $210000 \mathrm{~N} \cdot \mathrm{mm}^{-2}$ it was observed that the

Table 4. Steel X10CrMoVNb9-1; samples P21 and P6.

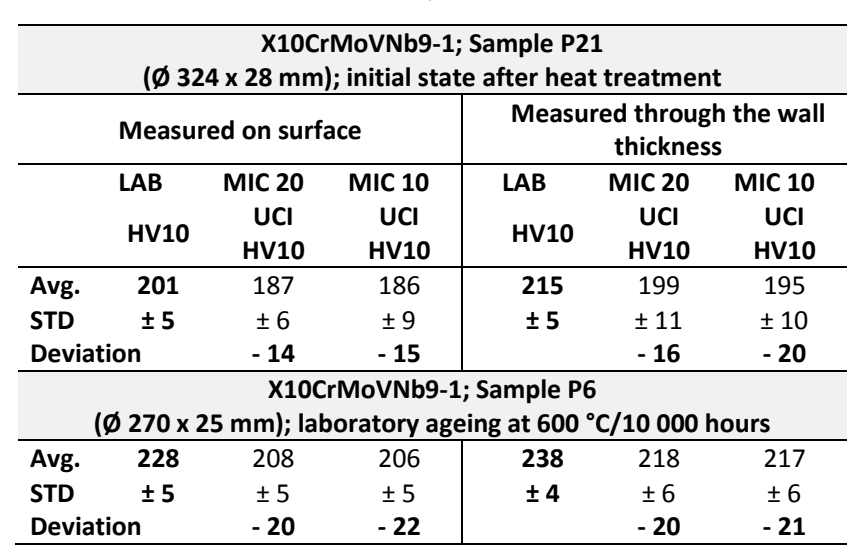

Table 5. Steel X10CrWMoVNb9-2; samples BT3 and T33.

\begin{tabular}{|c|c|c|c|c|c|c|}
\hline \multicolumn{7}{|c|}{$\begin{array}{c}\text { X10CrWMoVNb9-2; Sample BT3 } \\
(\varnothing 350 \times 39 \mathrm{~mm}) ; \text { laboratory ageing at } 650^{\circ} \mathrm{C} / 20000 \text { hours }\end{array}$} \\
\hline \multicolumn{4}{|c|}{ Measured on surface } & \multicolumn{3}{|c|}{$\begin{array}{l}\text { Measured through the wal } \\
\text { thickness }\end{array}$} \\
\hline & LAB & MIC 20 & MIC 10 & LAB & MIC 20 & MIC 10 \\
\hline \multirow{2}{*}{\multicolumn{2}{|c|}{ HV10 }} & UCl & UCI & \multirow{2}{*}{ HV10 } & $\mathrm{UCl}$ & $\mathrm{UCl}$ \\
\hline & & HV10 & HV10 & & HV10 & HV10 \\
\hline Avg. & 226 & 211 & 207 & 232 & 205 & 211 \\
\hline STD & \pm 2 & \pm 9 & \pm 9 & \pm 3 & \pm 5 & \pm 7 \\
\hline \multicolumn{2}{|c|}{ Deviation } & -15 & -19 & & -27 & -21 \\
\hline \multirow{2}{*}{\multicolumn{7}{|c|}{$\begin{array}{c}\text { X10CrWMoVNb9-2; Sample T33 } \\
(\varnothing 528 \times 94 \mathrm{~mm}) ; \text { laboratory ageing at } 650^{\circ} \mathrm{C} / 5033 \text { hours }\end{array}$}} \\
\hline & & & & & & \\
\hline Avg. & 223 & 204 & 198 & 230 & 205 & 216 \\
\hline STD & \pm 3 & \pm 12 & \pm 6 & \pm 3 & \pm 7 & \pm 6 \\
\hline \multicolumn{2}{|c|}{ Deviation } & -19 & -25 & & -25 & -14 \\
\hline
\end{tabular}


values of the deviations of both UCI hardness testers (Krautkrämer MIC20 and MIC10) vary in the inverse trend. The average value of the deviations is approximately $-13 \mathrm{HV}$ for 14Mo6-3 steel and $13 \mathrm{HV}$ for T23, T24 steels (see Table 6 Table 8).

c) Steels with $E=200000$ N.mm-2

The deviation values measured in steels with Young's

Table 6. Steel 14MoV6-3; samples PK1, EPR and EPC.

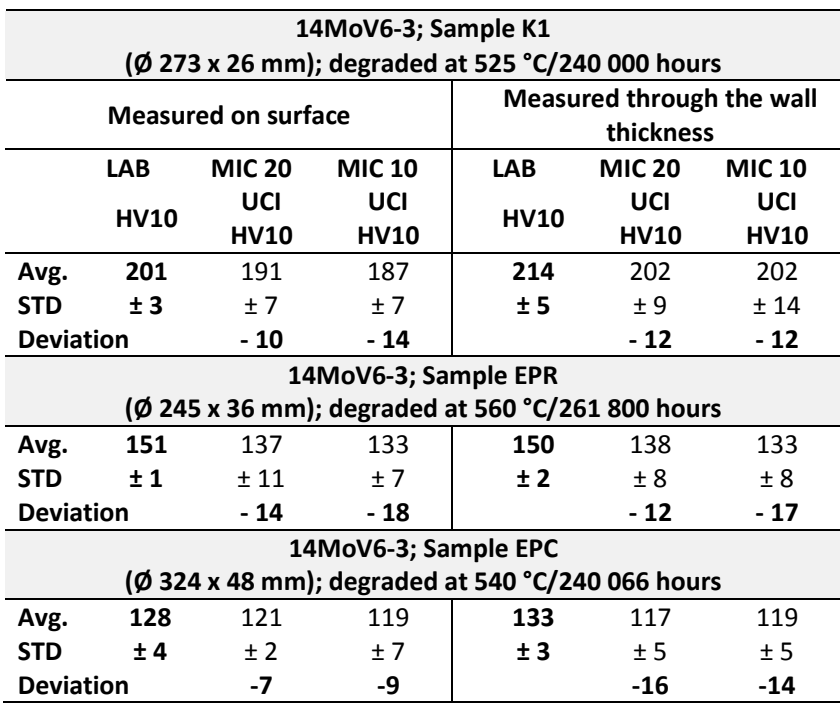

Table 7. Steel T23; samples V23 and D23.

\section{T23; Sample V23}

$(\varnothing 38 \times 5.6 \mathrm{~mm})$; initial state after heat treatment

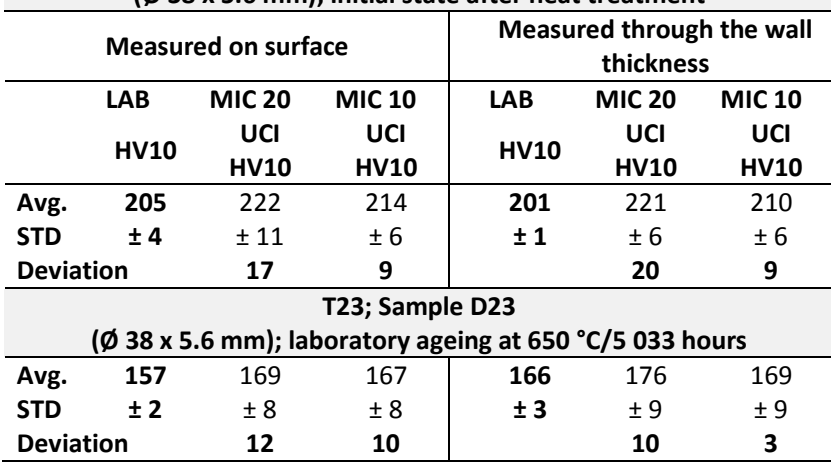

Table 8. Steel T24; samples V24 and D24.

\section{T24; Sample V24}

$(\emptyset 38 \times 5.6 \mathrm{~mm})$; initial state after heat treatment

\begin{tabular}{|c|c|c|c|c|c|c|}
\hline \multicolumn{4}{|c|}{ Measured on surface } & \multicolumn{3}{|c|}{$\begin{array}{c}\text { Measured through the wall } \\
\text { thickness }\end{array}$} \\
\hline & $\begin{array}{l}\text { LAB } \\
\text { HV10 }\end{array}$ & $\begin{array}{c}\text { MIC } 20 \\
\text { UCI } \\
\text { HV10 }\end{array}$ & $\begin{array}{c}\text { MIC } 10 \\
\text { UCI } \\
\text { HV10 }\end{array}$ & $\begin{array}{l}\text { LAB } \\
\text { HV10 }\end{array}$ & $\begin{array}{c}\text { MIC } 20 \\
\text { UCI } \\
\text { HV10 }\end{array}$ & $\begin{array}{c}\text { MIC } 10 \\
\text { UCI } \\
\text { HV10 }\end{array}$ \\
\hline Avg. & 229 & 250 & 239 & 228 & 243 & 231 \\
\hline STD & \pm 2 & \pm 12 & \pm 7 & \pm 5 & \pm 6 & \pm 11 \\
\hline Devia & & 21 & 10 & & 15 & 3 \\
\hline \multicolumn{7}{|c|}{$\begin{array}{c}\text { T24; Sample D24 } \\
(\varnothing 38 \times 5.6 \mathrm{~mm}) ; \text { laboratory ageing at } 650^{\circ} \mathrm{C} / 5033 \text { hours }\end{array}$} \\
\hline Avg. & 175 & 186 & 192 & 176 & 199 & 190 \\
\hline STD & \pm 2 & \pm 12 & \pm 8 & \pm 4 & \pm 11 & \pm 11 \\
\hline Devia & & 11 & 17 & & 23 & 14 \\
\hline
\end{tabular}

modulus of $200000 \mathrm{~N} \cdot \mathrm{mm}^{-2}$ of both UCI hardness testers (Krautkrämer MIC20 and MIC10) are similar. The average value of the deviations is approximately $-3 \mathrm{HV}$ (see Tables 9 and 10).

d) Steels with $E=193000 \mathrm{~N} \cdot \mathrm{mm}^{-2}$

In case of austenitic steel Super $304 \mathrm{H}$ with Young's modulus $193000 \mathrm{~N} \cdot \mathrm{mm}^{-2}$ it was observed that the measured values show large measurement errors. The standard deviation of the value measured by the UCI hardness tester is up to $59 \mathrm{HV}$. The measurement of hardness of austenitic steels is generally a problem due to their strengthening. The dynamic rebound method (Brinell method) was not carried out because specimens, on which the measurement was to be performed, did not reach the required minimum weight of $5 \mathrm{~kg}$ and minimum wall thickness $20 \mathrm{~mm}$. The average value of the deviations is very different (see Tables 11).

\section{CONCLUSION}

The original idea of practice that hardness measurement by mobile UCI hardness testers is independent of the values of Young's modulus has proven not to be entirely correct. The experimental results show the following (see Table 12). The larger is Young's modulus the larger is the negative deviation of the measured hardness. The explanation of this dependence is

Table 9. Steel X20CrMoV12-1; sample L1.

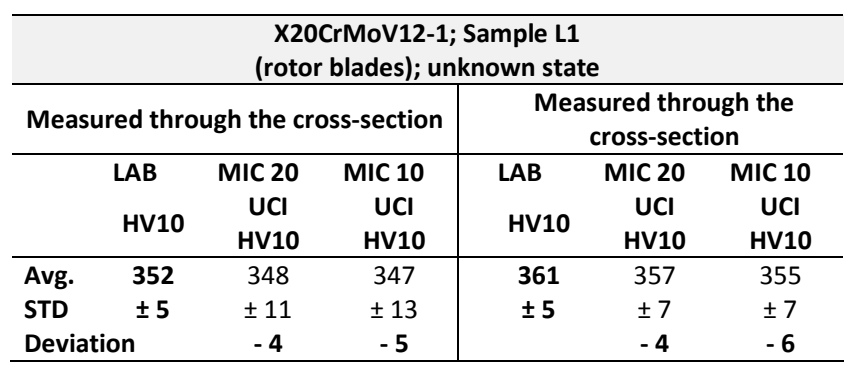

Table 10. Steel X5CrNiCuNb17-4-4; sample L2.

\begin{tabular}{|c|c|c|c|c|c|c|}
\hline \multicolumn{7}{|c|}{$\begin{array}{l}\text { X5CrNiCuNb17-4-4; Sample L2 } \\
\text { (rotor blades); unknown state }\end{array}$} \\
\hline \multicolumn{4}{|c|}{ Measured through the cross-section } & \multicolumn{3}{|c|}{$\begin{array}{l}\text { Measured through the } \\
\text { cross-section }\end{array}$} \\
\hline & LAB & MIC 20 & MIC 10 & LAB & MIC 20 & MIC 10 \\
\hline & & UCI & UCI & & UCI & UCI \\
\hline & HVIO & HV10 & HV10 & HVIO & HV10 & HV10 \\
\hline Avg. & 503 & 502 & 500 & 508 & 509 & 504 \\
\hline STD & \pm 7 & \pm 8 & \pm 7 & \pm 3 & \pm 10 & \pm 6 \\
\hline \multicolumn{2}{|c|}{ Deviation } & -1 & -3 & & 1 & -4 \\
\hline
\end{tabular}

Table 11. Steel Super 304H; sample 2030.

\begin{tabular}{lccc|ccc}
\hline \multicolumn{8}{c}{ Super 304H; Sample 2030 } \\
\hline \multicolumn{3}{c}{ Measured on surface } & \multicolumn{3}{c}{ Measured through the wall } \\
thickness \\
\hline LAB & MIC 20 & MIC 10 & LAB & MIC 20 & MIC 10 \\
& HV10 & UCl & UCl & HV10 & UCI & UCl \\
& HV10 & HV10 & HV10 & HV10 \\
\hline Avg. & 181 & 366 & - & 176 & 227 & - \\
STD & \pm 2 & \pm 59 & - & \pm 4 & \pm 32 & - \\
Deviation & 185 & - & & 49 & - \\
\hline
\end{tabular}


Table 12. A summary of the results of the average deviations.

\begin{tabular}{lcc}
\multicolumn{1}{c}{ Materials } & E [N.mm $\left.{ }^{-2}\right]$ & $\begin{array}{c}\text { Average deviations } \\
\text { HV10 }\end{array}$ \\
\hline $\begin{array}{l}\text { X10CrMoVNb9-1 (P91) } \\
\text { X10CrWMoVNb9-2 (P92) }\end{array}$ & 218000 & -21 \\
\hline 14MoV6-3 & 210000 & -13 \\
\hline $\begin{array}{l}\text { T23 } \\
\text { T24 }\end{array}$ & 210000 & 13 \\
\hline $\begin{array}{l}\text { X20CrMoV12-1 } \\
\text { X5CrNiCuNb17-4-4 }\end{array}$ & 200000 & -3 \\
\hline
\end{tabular}

evident from the Figure 2, which shows that the greater the frequency shift the smaller the measured hardness. Therefore, we can say that steel with a higher modulus of elasticity has a greater frequency shift. Therefore, we measured a lower hardness for steels with a higher Young's modulus.

The measured results showed the existing dependence of UCI hardness on Young's modulus. Although the dependence is very small, it is necessary to consider it and to perform the proposed calibration of UCI hardness testers using suitable calibration plates.

The measured results are summarized in Table 12. From the results it is possible to state that with increasing Young's modulus of elasticity $E$ the value of the negative deviation of hardness values measured by the UCI hardness tester increases in comparison with the values measured using a stationary (laboratory) tester. The dependence can be considered as linear. However, that doesn't apply in the case of T23 and T24 steels with Young's modulus of $210000 \mathrm{~N} \cdot \mathrm{mm}^{-2}$ where the deviation of UCI hardness varies in the opposite direction.

The general validity of these conclusions has not been confirmed in one case. T23 and T24 steels showed the deviation trend opposite to the deviation measured in 16MoV63 steel. The average value of the deviations is approximately -13 HV for 14Mo6-3 steel and 13 HV for T23, T24 steels.

Finding the reasons for this difference in deviations values is not yet completed. A possible cause could be a different wall thickness, because boiler tubes from these materials have a wall thickness of $5.6 \mathrm{~mm}$ and steam pipe-lines from other materials have wall thicknesses from 20 up to $80 \mathrm{~mm}$. The observation of the influence of different wall thicknesses (steam and boiler tubes), the influence of microstructure and verification of the real Young's modulus will be subjects for the further research.

Considering the above measured results, we propose the following groups of calibration plates:

1) Calibration plates for $9 \% \mathrm{Cr}$ martensitic steel - made from P91 (P92) steel: $\mathrm{E}=218000 \mathrm{~N} \cdot \mathrm{mm}^{-2}$

2) Calibration plates for low alloy $\mathrm{CrMoV}$ steels - made from 16MoV6-3 steel: $\mathrm{E}=210000 \mathrm{~N} \cdot \mathrm{mm}^{-2}$

3) Calibration plates for $2 \%$ Cr steels - made from $\mathrm{T} 23$ (T24) steel: $\mathrm{E}=210000 \mathrm{~N} \cdot \mathrm{mm}^{-2}$

4) Calibration plates for steels for rotor blades - made from X20CrMoV12-1 steel: $\mathrm{E}=200000 \mathrm{~N} \cdot \mathrm{mm}^{-2}$

It will be necessary to determine the hardness of these calibration plates at the lower and upper limit of practically measured values of $\mathrm{HV}$ hardness in operating conditions.

The rebound method was not carried out because specimens, on which the measurement was to be performed, did not reach the required minimum weight of $5 \mathrm{~kg}$. Measured values would be thus misleading.

These results are used in normative technical documentation for requirements for hardness measurements by portable hardness testers in Czech classic power plants.

\section{ACKNOWLEDGEMENT}

This work was supported by the Ministry of Education, Youth and Sport of the Czech Republic within the project No. LO1207 of the programme NPU1.

\section{REFERENCES}

[1] ASTM A1038 - 05. "Standard Practice for Portable Hardness Testing by the Ultrasonic Contact Impedance Method". West Conshohocken: ASTM International, 2005.

[2] S. Frank, "Mobile Hardness Testing Application Guide for Hardness Testers". General Electric Company [online]. 2005 [cit. 2015-02-13]. Available from: https://www.gemeasurement.com/sites/gemc.dev/files/hardnes s testing application guide english $0 . p d f$.

[3] K. Herrmann, "Hardness testing: principles and applications". Materials Park, Ohio: ASM International, 2011. ISBN 978-161503-832-9.

[4] M. Junek, "Posouzení životnosti VT parovodů v podmínkách creepového poškození". Diploma thesis. Praha: 2014. CTU in Prague, Faculty of mechanical engineering, Department of Material Engineering. p. 87.

[5] PA. PHILADELPHIA, "Power plant life management and performance improvement" Woodhead Pub. Ed. John E. Oakey, 2011, 684 p. ISBN 978-184-5697-266.

[6] Slide share. Slide share [online]. 2013 [cit. 2015-08-29]. Available from:

http://image.slidesharecdn.com/f4-131118222248phpapp02/95/hardening-14-638.jpg?cb=1384813955. 